\title{
Utilisation of Rapid Tests for Sexually Transmitted Infections: Promises and Challenges
}

\author{
Rosanna W. Peeling* \\ Department of Infectious and Tropical Diseases, The London School of Hygiene \& Tropical Medicine, Keppel Street, \\ London WC1E 7HT, UK
}

\begin{abstract}
The control of curable STIs in countries with high disease burden has been hampered by the lack of accessible STI laboratory services. Rapid tests that are sensitive, specific and easy to use have the potential to increase the specificity of syndromic management of STIs in symptomatic patients and increase access to screening of asymptomatic infection to prevent the development of long-term complications and to interrupt the chain of transmission of STIs in the population. Although most rapid tests for chlamydia and gonorrhoea have sub-optimal sensitivity, and are neither simple nor affordable, some rapid syphilis tests have been shown to have acceptable performance. These can be deployed to increase access to screening in settings where testing is not previously possible or where laboratory services are inconsistent. With more political commitment and technological advances made possible by increased funding and public and private product development partnerships, there is much optimism in the near future for point of care tests for STIs that can improve patient management and disease control.
\end{abstract}

The WHO estimates that more than 380 million new cases of sexually transmitted chlamydia, gonorrhea, syphilis and trichomoniasis occur worldwide every year [1]. An equal or greater number of viral sexually transmitted infections (STIs) such as those caused by herpes simplex virus and human papilloma virus also occur every year but efforts to estimate the annual incidence of these infections on a global basis have been limited.

\section{THE NEED FOR STI DIAGNOSTICS}

Most STIs are asymptomatic but their consequences are serious. Undiagnosed and untreated STIs can lead to long term complications (Table 1). While complications are relatively rare in men, infections in women can lead to pelvic inflammatory disease and tubal infertility, a condition, which, in some societies renders a woman worthless. STIs also cause serious adverse outcomes in pregnancy for both the women and their foetus or infant. Affordable curative therapy is available for the major bacterial STIs. Screening and early treatment are therefore critical for effective patient management to prevent the development of long term complications and to interrupt onward transmission. For infected individuals with symptoms, STI laboratory services are scarce in most high burden countries, requiring patients to travel long distances to access these services.

For countries with no or limited access to STI diagnostic services, the WHO recommends the use of a syndromic approach where patients are treated for all the major causes of a particular syndrome [2]. Syndromic management of STIs works well for urethral discharge, pelvic pain and

*Address correspondence to this author at the Department of Infectious and Tropical Diseases, The London School of Hygiene \& Tropical Medicine, Keppel Street, London WC1E 7HT, UK; Tel: +44 (0)20 7927 2529; Fax: +44 (0)20 7637 4314;

E-mail: rosanna.peeling@1shtm.ac.uk genital ulcer disease. Evaluations of the WHO flowcharts have shown that the algorithm for vaginal discharge lacks both sensitivity and specificity for the identification of women with $C$. trachomatis and $N$. gonorrhoeae infection $[3,4]$. In some areas of the world, syndromic management can result in as much as $98 \%$ overtreatment for chlamydia and gonorrhea in women presenting with vaginal discharge. Most women with this syndrome do not have these cervical infections, but suffer from vaginal infections (candidiasis, bacterial vaginosis or trichomoniasis). Vaginal infections can be diagnosed using a microscope (using Gram stained smears or wet preparation), or treated presumptively with metronidazole which is safe and inexpensive. Unfortunately it is not possible to diagnose gonorrhea or C. trachomatis infections at peripheral health services in most developing countries, since facilities are not available for culture, antigen detection or nucleic acid amplification tests. Microscopy of Gram stained smears can be used to diagnose gonorrhea. Although microscopy of urethral smears has a sensitivity of $95 \%$ compared to culture, it is at best only about $50 \%$ sensitive in endocervical specimens from women. There is a great need for simple, cheap, point-of-care tests for these infections, especially in women, to increase specificity, and reduce over treatment.

Since not all causes of the syndrome of genital discharge are sexually transmitted, partner notification is often not done. Another advantage of having a rapid, specific diagnosis of for a STI at the time of the clinic visit, is that partner notification can be initiated without delay.

In addition to syndromic management, in recent years there have been a number of new trends in the provision of STI services where rapid tests may add value.

\section{Express Visit Option}

Some STI clinics are now offering express visits in which the clinic attenders are tested for STIs without a physical 
Table 1. Long Term Complications from Major Bacterial STIs

\begin{tabular}{|c|c|c|c|}
\hline \multirow{2}{*}{ STIs } & Men & Women & \multicolumn{2}{|c|}{ Long Term Complications } \\
\cline { 2 - 4 } & Infant/Children \\
\hline \hline Chlamydia Gonorrhea & Urethral stricture, epididymitis & $\begin{array}{c}\text { Pelvic inflammatory disease, chronic pelvic pain, } \\
\text { ectopic pregnancy, tubal infertility }\end{array}$ & Opthalmia neonatorum, pneumonia \\
\hline Syphilis & $\begin{array}{c}\text { Neurosyphilis, cardiovascular } \\
\text { manifestations, multi-organ } \\
\text { involvement }\end{array}$ & $\begin{array}{c}\text { Neurosyphilis, cardiovascular manifestations, } \\
\text { multi-organ involvement; adverse pregnancy } \\
\text { outcomes: stillbirth, low birth weight, prematurity }\end{array}$ & Congenital syphilis \\
\hline
\end{tabular}

examination [5]. These services may prove useful as waiting time is reduced although it remains to be seen whether not having a physical examination is detrimental. Rapid tests can offer testing and treatment in the same visit, and partner notification can be initiated without delay.

\section{Pharmacies}

In the developing world, many pharmacies are surrogate clinics where the pharmacists prescribe drugs based on the self-reported symptoms of their customers $[6,7]$. Pharmacies offer STI testing services or sell STI tests for home testing. Unfortunately, due to lack of regulatory oversight, many pharmacies use and sell tests with sub-optimal sensitivity, giving their clients false negative results [8]. These infected individuals may develop long term complications and continue to transmit infection within their community.

\section{Internet Services}

In recent years, the internet has offered opportunities for the diagnosis of STIs [9-14]. There are many websites offering STI testing services or offer tests for home testing. These services cater to those who wish for confidentiality and avoid stigma. Some excellent services are offered by public health programs but most online services and tests sold over the internet are of dubious quality due to the lack of regulation [8].

\section{Venue Based Testing}

Studies have shown that venue based screening of high risk individuals for STIs can be effective $[15,16]$. Since high risk individuals often do not have good health seeking behaviour, rapid tests offer an advantage in that testing and treatment can be offered at venues frequented by them.

\section{INTEGRATED APPROACH FOR SCREENING OF HIV AND STIs}

Given the interaction of different STIs and HIV, so that the individuals who test positive for one STI should immediately be screened for other STIs including HIV [1723].

\section{THE PROMISES OF RAPID TESTS FOR STIS}

If rapid tests can be developed for use in health centres without traditional laboratory services, they should meet the "ASSURED" criteria developed by the WHO STD Diagnostics Initiative (SDI) (www.who.int/std_diagnostics) [24, 25] (Table 2).

The tests need to be affordable. The 2004 World Health report shows that unaffordability and inaccessibility are two major reasons why health services fail [26]. They need to have acceptable performance and reliability in that the results are reproducible. False negative tests (low sensitivity) are problematic as most clinicians accept test results over clinical findings, and may fail to manage these cases appropriately. False positive tests (low specificity) leads to inaccurate diagnosis, over treatment and possibly stigma and blame. Ideally specificity should be greater than $98 \%$ when integrated with clinical information. To increase access to diagnostics, it would be important for the ideal test to be stable for long periods at room temperature and are simple to perform with minimal training and no or minimal equipment. The ideal test should also be a multiplex test for all the major causes of specific STI syndromes.

Table 2. The Ideal Rapid Test for STIs: ASSURED Criteria

$$
\begin{aligned}
& \mathbf{A}=\underline{\text { Affordable }} \\
& \mathbf{S}=\underline{\text { Sensitive }} \\
& \mathbf{S}=\underline{\text { Specific }} \\
& \mathbf{U}=\text { User-friendly (simple to perform in a few steps with minimal training) } \\
& \mathbf{R}=\text { Robust and rapid (thermostable and results available in less than } 30 \mathrm{~min} \text { ) } \\
& \mathbf{E}=\text { Equipment-free } \\
& \mathbf{D}=\text { Deliverable to those who need them }
\end{aligned}
$$

There has been much debate whether rapid or near patient tests can improve the control of STIs [27-29]. The promises of rapid tests are many but so are their limitations. Table 3 shows settings where rapid tests can improve patient management and STI control.

\section{STATUS OF CURRENT RAPID STI TESTS}

\section{Syphilis}

Syphilis in pregnancy is a major cause of adverse pregnancy outcome in many developing countries. A recent study in Tanzania found that it was responsible for some $50 \%$ of all stillbirths [30]. In most countries non-treponemal tests such as the Rapid Plasma Reagin (RPR) or the Venereal Diseases Research Laboratory (VDRL) slide test is used to screen pregnant women. Women who test positive at peripheral clinics are treated without confirmatory testing as treponemal tests are not widely available. Given the importance of early treatment to prevent stillbirth and congenital syphilis, and the efficacy and safety of intramuscular benzathine penicillin, this is acceptable practice, even though it may lead to over treatment of biological false positive cases due to malaria, leprosy, viral pneumonia or immune disorders [31]. In developed countries, screening and treatment of pregnant women for 
Table 3. Settings where Rapid STI Tests Can Make a Difference

\begin{tabular}{|l|l|l|}
\hline \multicolumn{1}{|c|}{ Settings } & \multicolumn{1}{|c|}{ Promises } & \multicolumn{1}{c|}{ Success Criteria } \\
\hline \hline $\begin{array}{l}\text { No testing possible } \\
\text { (e.g. primary care) }\end{array}$ & Increase access to testing & - cases detected and treated \\
\hline $\begin{array}{l}\text { Syndromic management } \\
\text { (e.g. health centres) }\end{array}$ & $\begin{array}{l}\text { - improves specificity of diagnosis } \\
\text { - enable partner notification without delay } \\
\text { - reduce overuse of antibiotics }\end{array}$ & $\begin{array}{l}\text { - \% overtreatment reduced } \\
\text { - reduced delay in partner notification and treatment }\end{array}$ \\
\hline $\begin{array}{l}\text { Laboratory services available } \\
\text { but need to return for results } \\
\text { clinics in urban centres, } \\
\text { district and referral hospitals) }\end{array}$ & $\begin{array}{l}\text {-avoid low return rates for test results and treatment } \\
\text { - prevent development of complications } \\
\text { - enable immediate partner notification and } \\
\text { treatment }\end{array}$ & $\begin{array}{l}\text { - number of babies saved from still birth and congenital syphilis } \\
\text { - number of complications, such as cases of pelvic inflammatory } \\
\text { - numberer of partners treated to prevent re-infection }\end{array}$ \\
\hline $\begin{array}{l}\text { Outbreak investigation, } \\
\text { monitor disease trends and } \\
\text { effectiveness of novel } \\
\text { interventions }\end{array}$ & $\begin{array}{l}\text { - facilitate rapid situation analysis } \\
\text { - utility in outreach and outbreak investigations }\end{array}$ & $\begin{array}{l}\text { - disease trends available for rational design of control programs } \\
\text { - increased efficacy of control and prevention programs }\end{array}$ \\
\hline
\end{tabular}

syphilis remains cost-effective even when the prevalence is low $[32,33]$. In Tanzania, where the prevalence of syphilis in pregnant women was found to be approximately $8 \%$, it is among the most cost-effective health interventions available, at less than US\$11 per disability-adjusted life year (DALY) saved [34].

Given the serious consequences of syphilis in pregnancy, prenatal screening for syphilis is official health policy in almost all countries. However, the implementation of this policy is far from ideal in the developing world. It has been estimated that approximately $30 \%$ of pregnant women are screened for syphilis in sub-Saharan Africa [35, 36]. A study in Bolivia showed that although $76 \%$ of the study population received antenatal care, only $17 \%$ were screened for syphilis during pregnancy [37]. There are many reasons for the low rates of antenatal screening for syphilis even though RPR and VDRL tests are affordable and can give a result in 8-10 minutes. Performing a non-treponemal test requires a laboratory with:

\section{Trained personnel;}

2. Refrigeration for storage of reagents;

3. Electricity to run equipment: refrigerator, centrifuge to separate serum from whole blood and a shaker to perform the serology

Since such facilities are generally not available in rural health centres and health posts, blood or serum samples have to be transported to district or regional facilities for testing. Results are therefore often available only days or weeks after the specimens are taken. Studies showed that, even when this simple policy was followed, only a small proportion of infected women received treatment when RPR testing was performed off site, since many do not return for their results or specimens or results are lost in transit [38]. The delay in obtaining test results not only results in delay in treatment for the patients but also continued transmission of infection. A series of demonstration projects showed that decentralization of syphilis screening followed by immediate treatment can be effective in reducing perinatal mortality [39-42].

Where laboratory services are not available, the new, simple, point-of-care treponemal tests, in a dipstick or cassette format, provide an important opportunity to improve access to testing. Recent evaluations have shown that some rapid syphilis tests, have sensitivities of $85-99 \%$ and specificities of $93-100 \%$ compared to laboratory-based treponemal tests [43-48]. These tests do not require equipment, can be transported and stored at room temperature and can be used with whole blood obtained by finger pricks, although sensitivity can decrease by $10-20 \%$ [49]. Rapid tests, unlike RPR or VDRL, do not give false negative results with specimens containing high level of antibodies, a phenomenon known as the prozone effect, However, a disadvantage of these rapid treponemal tests is that they cannot be used to distinguish between recent active infection and past treated infection, as treponemal antibodies persist for years,

But given the serious consequences of failure to detect and treat infected pregnant women and the rarity of adverse drug effects, the benefits of a rapid treponemal test that is simple to perform and enable immediate treatment clearly outweigh the risks of over-treatment. Their greatest value is in increasing the coverage of syphilis screening in rural areas of developing countries where access to laboratory services is a problem and in increasing the proportion of cases treated when return rates are low. More information on the performance and operational characteristics of these rapid tests can be found on the SDI website: www.who.int/std_diagnostics.

Rapid treponemal tests cost more than RPR or VDRL tests but they have been shown to be cost-effective in a number of recent studies and have better sensitivity for early syphilis than non-treponemal tests [50-54]. They are particularly cost-effective when used in combination with HIV tests in Prevention of Mother to Child Transmission of HIV programs to avoid babies avoiding HIV [55]. They will be important tools for the elimination of congenital syphilis and for outreach to reverse the trend of syphilis in high risk populations.

\section{Chlamydia and Gonorrhea}

Unlike other STIs, there has been substantial investment in and commercialization of state of the art diagnostic technology for genital chlamydial and gonococcal infections. 
This has largely been driven by a market in developed countries where screening for genital chlamydial infections is mandated by national STI management guidelines [56, 57]. Four diagnostic companies have marketed nucleic acid amplified tests (NAATs) for the diagnosis and screening of genital chlamydial and gonococcal infections. These tests can detect 10-100 bacteria and have specificities greater than $98 \%[58,59]$. With the sensitivity of NAATs, it is now possible to use non-invasive specimens such as urine and self- or physician collected vaginal swabs instead of urethral or cervical swabs. The ease of collection makes it possible to collect specimens at outreach settings or for patients to collect specimens at home and send them through the post. Both are acceptable to patients and cost-effective [60-67]. However, these tests require sophisticated equipment, highly trained personnel and are costly. They are not widely available in most of the developing world where the disease burden of bacterial STIs is greatest.

There are more than twenty rapid chlamydial and gonococcal tests on the market today. Recent evaluations showed that most of them have adequate specificity but with the exception of one test that has a sensitivity of more than $80 \%$ for vaginal swabs compared to urine PCR in women, most have sub-optimal sensitivity of approximately $50 \%$ $70 \%$ compared to PCR for cervical swabs and $33 \%-70 \%$ for vaginal swabs [68-73]. NAATs are ideal for screening since they have high sensitivity. However, a study conducted in the US showed that there may be a Rapid Test Paradox [74]. Using a decision analysis in a US STD clinic setting, Gift et al. showed that screening for chlamydia in women using a rapid chlamydia test with $65 \%$ sensitivity can result in more cases of chlamydia being treated compared to a NAAT with 90\% sensitivity, since NAATs have a much longer turn around time and many patients failed to return for their test results. Moreover, 3\% of those infected had already developed pelvic inflammatory disease by the time they returned.

Most rapid tests for chlamydia and gonorrhea are antigen detection tests and their lower limit of detection is between $10^{4}$ to $10^{5}$ bacteria. By using these rapid tests in a high prevalence setting, giving treatment at the point of care and initiating partner notification, it may be possible to eliminate those with high bacterial loads from the chain of transmission within the community. This is particularly important in a high prevalence population where patient return rates for test results and treatment are low. Mathematical models show that the required sensitivity of a rapid test is low if there is significant STI transmission during the delay in treatment and/or few women return for treatment $[75,76]$. Hence in high risk populations with significant possibility of transmission on a daily basis, the use of a rapid test with moderate sensitivity may be warranted.

Over the last few decades, $N$. gonorrhoeae has shown a tremendous ability to develop resistance to different classes of antimicrobial agents. Resistant genotypes have now spread around the world. The lack of laboratories in many developing countries with the capacity to perform antimicrobial susceptibility testing is a concern. The development of rapid tests that can detect resistant genotypes is a priority.

\section{Trichomoniasis and Bacterial Vaginosis}

Trichomoniasis and bacterial vaginosis (BV) have been shown to be a risk factor in the transmission of HIV and other STIs [77-79]. Women presenting with vaginal discharge can be diagnosed for trichomonas by microscopy using wet mount, culture or nucleic acid based tests, with or without amplification. Rapid antigen detection tests are commercially available for use outside of laboratory settings. They have been shown to have sensitivities of $70-83 \%$ and specificities of $93-99 \%$ compared to a combined reference standard of culture and wet mount $[80,81]$. BV can be diagnosed clinically using the Amsel criteria, based on having three of four presentations: a homogeneous white adherent discharge, vaginal fluid $\mathrm{pH}$ of $>4.5$, a positive amine test, detected using $\mathrm{KOH}$, and the presence of clue cells using microscopy [82]. BV can also be diagnosed by microscopy using the Nugent scoring system to assess the proportion of small Gram-negative or Gram variable coccobacilli and curved bacilli in vaginal flora compared to large Gram-positive rods (Lactobacilli spp).which are normally found in normal flora. When microscopy is not available, $\mathrm{pH}$ and the $\mathrm{KOH}$ test can be used to support the clinical diagnosis of $\mathrm{BV}$ and these are inexpensive tests. A number of rapid tests for BV are commercially available. They have been shown to have sensitivities of $82-91 \%$ and specifities of $62-95 \%$ compared to the Nugent criteria [83$86]$. These tests are costly and may not offer much advantage in term of specificity and rapidity compared to $\mathrm{pH}$ and $\mathrm{KOH}$ tests.

\section{Herpes Simplex}

Two rapid serologic tests for HSV 2 have been marketed. Serologic tests are useful in the identification of discordant couples but the role of a rapid serologic test for HSV is unclear $[87,88]$.

\section{RAPID TESTS FOR STIS: THE CHALLENGES}

If rapid tests can make a difference, and many rapid tests for STIs are currently commercially available, why aren't they used more widely? The challenges faced by policy makers and control program managers are many and they include:

\section{Political Commitment}

STI programs in most countries are neglected compared to other infectious diseases such as HIV, malaria and tuberculosis. The tools for the elimination of congenital syphilis are available and prevention through prenatal screening and treatment has been shown in numerous studies to be as cost-effectiveness as childhood interventions such as measles immunisation. However, the lack of political commitment has resulted in the programs not being given a high priority for funding. This is especially true in countries faced with a large number of competing priorities for limited resources. Without the resources and commitment for implementation, as many as 500,000 babies die per year die of congenital syphilis in sub-Saharan Africa and many more elsewhere in the developing world $[89,90]$. 


\section{Costs}

Rapid tests are in most cases more expensive than laboratory tests as they are single use tests. Laboratory tests are often batched which saves on costs and hands-on time. Decentralisation of testing at different levels of the health care system can also require additional resources.

\section{Test Performance}

Currently most rapid tests have suboptimal performance compared to laboratory tests. Although one expects some trade off in performance, especially in sensitivity, for rapidity of obtaining a test result, false negative or false positive results for STIs can lead to serious psychosocial consequences for the individual and their sex partners the control program. The threshold of test performance at which rapid STI tests would be of benefit depends largely on the setting and the patient return rates.

\section{Coherency in Program Design and Implementation}

STIs patients seek care at different types of clinics and settings, ranging from STI clinics, gynecology clinics, prenatal clinics to physicians offices and, more recently, the internet. The largest proportion of patients probably present to physician's offices. An effective STI control program needs to be able to meet the needs of those who seek care wherever they present. It is important to have a welldesigned control program with a coherent plan and welldefined responsibilities to provide comprehensive training to those who work at different care settings to ensure that the management of STI does not fall between the cracks of these diverse programs.

The role of the tertiary and district level laboratories is critical in assuring the proficiency of the health workers performing rapid tests. In conditions of high heat and humidity, it is important to develop a system for quality control to ensure that where rapid test quality is not compromised by long term storage in peripheral centres.

Even where there is political commitment and resources are available; there are often operational and administrative difficulties in delivery of health services due to an inadequate health care infrastructure plagued by staff shortages, lack of proper training and supervision, frequent stock-out of tests and medicines [91-93]. This means good leadership, well-trained staff, good supply chain management, quality assurance programs, and surveillance that can monitor the effectiveness of the control program or specific interventions.

STIs have been shown to play a role in increasing the risk of HIV transmission [17]. Hence opportunities for integration of STI and HIV screening at all levels of health care must not be missed. This approach gives at risk populations a single point of access to information and services. For programme managers, integrated services are more cost-effective than if the training and quality assurance of testing were provided independently. In particular, rapid syphilis screening can be integrated into rapid HIV testing for Prevention of Mother to Child Transmission (PMTCT) programmes to avoid the tragedy of babies avoiding HIV but dying of syphilis [55]. Since funding for most programs are vertical, synergies between program such as those between HIV and STIs are often lost.

\section{Regulatory Oversight}

In most countries in the developing world, regulatory oversight is limited or non-existent for in vitro diagnostics for infectious diseases, other than those used for blood banking [94, 95]. The quality of laboratory-based tests is often better regulated through the institution of quality management systems. But this is not the case with rapid tests. As a result, many poor quality rapid tests are sold cheaply. They are bought and used without evidence of effectiveness. Companies with good quality tests will find it difficult to compete in a market that is flooded with these poor quality tests.

\section{LESSONS LEARNT FROM HIV TESTS}

The need for rapid HIV tests to increase access to screening has driven substantial private sector investment into production of high quality rapid HIV tests. The WHO recommends a three phase approach to the use of HIV tests:

1. Evaluation of test performance in a reference laboratory using prospectively collected or archived specimens to facilitate test selection and development of testing algorithm

2. Pilot testing algorithm at the point of service

3. Implementation of the testing algorithm with ongoing external quality assurance and monitoring

This phased approach should be adopted by control programs for all rapid STI tests. An assessment of this approach in 11 countries in Africa showed that in general, appropriate tests were selected and test algorithm worked well [96]. However, only two of 11 countries had external quality assurance programs.

\section{OPTIMISM FOR THE FUTURE}

\section{Commitment to Invest in Primary Health Care and Laboratories Services}

On the $30^{\text {th }}$ anniversary of the Declaration of Alma-Ata on Primary Health Care in 1978, the World Health Organization is spearheading a renewal of the commitment towards strengthening health systems and in particular developing essential health care packages at primary health care level [97]. This may include rapid tests for HIV, syphilis, Malaria (where it is endemic), a test for anaemia and the capacity to transport sputum to a district level facility to test for tuberculosis.

In some developing countries such as Malawi, an essential health package developed by the Ministry of Health includes a package of essential medical laboratory services [98]. Such a package includes:

- $\quad$ Emphasizing the importance of laboratory testing for accurate diagnosis

- Ensuring sufficient financial resources are made available

- Implementation of laboratory training programmes

- Regular supervision of laboratory staff

- Routine monitoring of test quality

- $\quad$ Establishing a system for laboratory accreditation 


\section{- $\quad$ Evaluation of affordable, rapid diagnostic tests}

There is also a commitment on the elimination of congenital syphilis which is gathering momentum [99]. Rapid tests to increase access to prenatal screening are tools critical to the success of the elimination program.

\section{Technological Advances}

The genomes of major bacterial STIs have been sequenced [100-102]. Investments in diagnostics target research will lead to the discovery of novel diagnostic targets or biomarkers, which can complement recent advances in rapid detection technologies driven and funded largely through anti-bioterrorism activities. Several companies have microfluidic platforms that can test for several pathogens using a single specimen [103].

\section{More Funders and More Test Developers}

Diagnostics researches are often undervalued by both industry and by governments. The Lewin report on the Value of Diagnostics, noted that while diagnostics comprise less than $5 \%$ of hospital costs and about $1.6 \%$ of all USA Medicare costs, their findings influence $60-70 \%$ of health care decision-making [104]. Similarly in the developing world, a report in Malawi showed that only $6 \%$ of health expenditures at a district hospital are spent on diagnosis [105]. In recent years, there has been a growing recognition that the lack of appropriate diagnostics is a major barrier to improvements in global health. As a result, there are now more funding and public and private product development partnerships in this field. The Bill \& Melinda Gates Foundation organized a Global Health Diagnostics Forum, and published a supplement with the Nature Publishing Group on the potential impact of improved diagnostics for the developing world [106-111]. The Grand Challenges funded by the Bill \& Melinda Gates Foundation provides funding for novel test platforms and multiplex tests. A number of non-profit agencies such as the Foundation for Innovative New Diagnostics (FIND), the Program for Appropriate Technology in Health (PATH), the Infectious Diseases Research Institute (IDRI) are now investing in appropriate technologies for diagnostics which include tuberculosis, malaria, sexually transmitted infections and other neglected tropical diseases.

\section{CONCLUSIONS}

The control of curable STIs in countries with high disease burden has been hampered by the lack of accessible STI laboratory services. Rapid tests that fulfil the ASSURED criteria have the potential to increase the specificity of syndromic management of STIs in symptomatic patients and increase access to screening of asymptomatic infection to prevent the development of long-term complications and to interrupt the chain of transmission of STIs in the population. Increased access to testing and treatment of STIs will be important in the Global Elimination of Congenital Syphilis and will assist countries with the attainment of their Millennium Development Goals by reducing mortality under 5 , improving reproductive health and reducing the risk of HIV transmission. Although most rapid tests for chlamydia and gonorrhea have sub-optimal sensitivity, and are not simple or affordable, some rapid syphilis tests are closed to fulfilling the ASSURED criteria and can be deployed to increase access to screening in settings where testing is not previously possible or where laboratory services are inconsistent and patients return rates are low. With more political commitment and technological advances made possible by increasing number of funders and product development partnerships, there is much optimism in the near future for point of care tests for STIs that can improve patient management and disease control.

\section{REFERENCES}

[1] World Health Organization. Global prevalence and incidence of selected curable sexually transmitted infections: overview and estimates. Geneva: WHO, 2002. (WHO/HIV_AIDS/2001.02).

[2] World Health Organization. Guidelines for the management of sexually transmitted infections. Geneva: World Health Organization; 2001 (WHO/HIV_AIDS/2001.01)

[3] Hawkes S, Morison L, Foster S, et al. Reproductive-tract infections in women in low-income, low-prevalence situations: assessment of syndromic management in Matlab, Bangladesh. Lancet 1999; 354 : 1776-81.

[4] Pepin J, Deslandes S, Khonde N, et al. Low prevalence of cervical infections in women with vaginal discharge in West Africa: implications for syndromic management. Sex Transm Infect 2004; 80: 230.

[5] Shamos SJ, Mettenbrink CJ, Subiadur JA, Mitchell BL, Rietmeijer CA. Evaluation of a testing-only "express" visit option to enhance efficiency in a busy STI clinic. Sex Transm Dis 2008; 35: 336.

[6] Van Bergen JE, Postma MJ, Peerbooms PG, Spangenberg AC, Tjen-ATak J, Bindels PJ. Effectiveness and cost-effectiveness of a pharmacybased screening programme for Chlamydia trachomatis in a high-risk health centre population in Amsterdam using mailed home-collected urine samples. Int J STD AIDS 2004; 15: 797-802.

[7] Adams EJ, Garcia PJ, Garnett GP, Edmunds WJ, Holmes KK. The cost-effectiveness of syndromic management in pharmacies in Lima, Peru. Sex Transm Dis 2003; 30: 379-87.

[8] Michel C-EC, Saison FG, Joshi H, Mahilum-Tapay LM, Lee HH. Pitfalls of internet-accessible diagnostic tests: inadequate performance of a CE-marked Chlamydia test for home use. Sex Transm Infect 2009; 85: 187-9.

[9] Gaydos CA, Arora N, Owens SL, Peeling RW, Holmes KK. Can the Internet be Used to Access Testing for sexually transmitted infections? Abstract presented at the meeting of the British Association for Sexual Health and HIV and the American STD Association: New York, USA 2008.

[10] Peeling RW. Testing for sexually transmitted infections: a brave new world? Sex Transm Infect 2006; 82: 425-30.

[11] Levine DK, Scott KC, Klausner JD. Online syphilis testing confidential and convenient. Sex Transm Dis 2005; 32: 139-41.

[12] Gaydos CA, Dwyer K, Barnes M, et al. Internet based screening for Chlamydia trachomatis to reach non-clinic populations with mailed self-administered vaginal swabs. Sex Transm Dis 2006; 33: 451-7.

[13] Rietmeijer CA, Bull SS, McFarlane M, Patnaik JL, Douglas JMJ. Risks and benefits of the internet for populations at risk for sexually transmitted infections (STIs): results of an STI clinic survey. Sex Transm Dis 2003; 30: 15-9.

[14] Koekenbier RH, Davidovich U, van Leent EJ, Thiesbrummel HF, Fennema HS. Online-mediated syphilis testing: feasibility, efficacy, and usage. Sex Transm Dis 2008; 35: 764.

[15] Rietmeijer CA, Hopkins E, Geisler WM, Orr DP, Kent CK. Chlamydia trachomatis positivity rates among men tested in selected venues in the United States: a review of the recent literature. Sex Transm Dis 2008; 35: S8.

[16] Khan MR, Rasolofomanana JR, McClamroch KJ, et al. High-risk sexual behavior at social venues in Madagascar. Sex Transm Dis 2008; 35: $738-45$

[17] Barnabas RV, Wasserheit JN. Riddle of the Sphinx revisited: the role of STDs in HIV prevention. Sex Transm Dis 2009; 36: 365.

[18] Branger J, van der Meer JT, van Ketel RJ, Jurriaans S, Prins JM. High incidence of asymptomatic syphilis in HIV-infected MSM justifies routine screening. Sex Transm Dis 2009; 36: 84.

[19] Kendrick SR, Kroc KA, Withum D, Rydman RJ, Branson BM, Weinstein RA. Outcomes of offering rapid point-of-care HIV testing in a sexually transmitted disease clinic. J Acquir Immune Defic Syndr 2005; $38: 142$. 
[20] Huhn GD, McIntyre AF, Broad JM, et al. Factors associated with newly diagnosed HIV among persons with concomitant sexually transmitted diseases. Sex Transm Dis 2008; 35: 731.

[21] Klausner JD. Frequency of syphilis testing in HIV-infected patients: more and more often. Sex Transm Dis 2009; 36: 86.

[22] Ruan Y, Cao X, Qian HZ, et al. Syphilis among female sex workers in southwestern China: potential for HIV transmission. Sex Transm Dis 2006; 33: 719 .

[23] Chen XS, Yin YP, Tucker JD, et al. Detection of acute and established HIV infections in STD clinics in Guangxi, China: implications for screening and prevention of HIV infection. J Infect Dis 2007; 196: 1654-61.

[24] Peeling RW, Mabey D, Holmes KK. Diagnostics for sexually transmitted infections: the way forward. Sex Transm Infect 2006; 82(Suppl V): 1-6.

[25] Kettler H, White K, Hawkes S. Mapping the landscape of diagnostics for sexually transmitted infections. $2004 \mathrm{WHO} / \mathrm{TDR}$ publication.

[26] World Bank. World Development Report 2004: Making Services Work for Poor People. New York: Oxford University Press for the World Bank 2004

[27] Ward P. Near-patient tests will improve the control of sexually transmitted infections: the arguments in favour. Sex Transm Infect 2006; 82: 506-8.

[28] Dean GL. Near-patient tests will not improve the control of sexually transmitted infections. Sex Transm Infect 2006; 82: 509-12.

[29] Vickerman P, Peeling RW, Watts C, Mabey D. Detection of Gonococcal Infection: Pros and cons of a rapid test. Mol Diagn 2005; 9 : 175-9.

[30] Watson-Jones D, Changalucha J, Gumodoka B, et al. Syphilis in pregnancy in Tanzania. I: impact of maternal syphilis on outcome of pregnancy. J Infect Dis 2002; 186: 940-7.

[31] Peeling RW, Ye H. Diagnostic tools for preventing and managing maternal and congenital syphilis: an overview. Bull World Health Organ 2004; 82: 439-46.

[32] Stray-Pedersen B. Economic evaluation of maternal screening to prevent congenital syphilis. Sex Transm Dis 1983; 10: 167-72.

[33] Connor N, Roberts J, Nicoll A. Strategic option for antenatal screening for syphilis in the United Kingdom: a cost effectiveness analysis. J Med Screen 2000; 7: 7-13.

[34] Terris-Prestholt F, Watson-Jones D, Mugeye K, et al. Is antenatal syphilis screening still cost-effective in Sub-Saharan Africa? Sex Transm Infect 2003; 79: 375-81.

[35] Gloyd S, Chai S, Mercer MA. Antenatal syphilis in sub-Saharan Africa: missed opportunities for mortality reduction. Health Policy Plann 2001; 16: 29-34.

[36] Schmid G. Economic and programmatic aspects of congenital syphilis prevention. Bull World Health Organ 2004; 82: 402-9.

[37] Southwick KL, Blanco S, Santander A, et al. Maternal and congenital syphilis in Bolivia, 1996: prevalence and risk factors. Bull World Health Organ 2001; 79: 33-42.

[38] Fonn S. A blood-result turn-around time survey to improve congenital syphilis prevention in rural area. South Afr Med J 1996; 1: 67-71.

[39] Hira SK, Bhat GJ, Chikamata DM, Nkowane B, Tembo G, Perine PL. Syphilis intervention in pregnancy: Zambian demonstration project. Genitourin Med 1990; 66: 159-64.

[40] Jenniskens F, Obwaka E, Kirisuah S, et al. Syphilis control in pregnancy: decentralization of screening facilities to primary care level, a demonstration project in Nairobi, Kenya. Int J Gynecol Obstet 1995; 48(Suppl): S121-8.

[41] Fitzgerald DW, Behets F, Preval J, Schulwolf L, Bommi V, Chaillet P. Decreased congenital syphilis incidence in Haiti's rural Artibonite Region following decentralized prenatal screening. Am J Public Health 2003; 93: 444-6.

[42] Temmerman M, Fonck K, Bashir F, et al. Declining syphilis prevalence in pregnant women in Nairobi since 1995: another success story in the STD field? Int J STD AIDS 1999; 10: 405-8.

[43] Siedner M, Zapitz V, Ishida M, De la Roca R, Klausner JD. Performance of rapid syphilis tests in venous and whole blood specimens. Sex Transm Dis 2004; 31: 557-60.

[44] Montoya PJ, Lukehart SA, Brentlinger PE, et al. Comparison of the diagnostic accuracy of a rapid immunochromatographic test and the rapid plasma regain test for antenatal syphilis screening in Mozambique. Bull World Health Organ 2006; 84: 97-104.

[45] Herring AJ, Ballard RC, Pope V, et al. A multi-centre evaluation of nine rapid, point-of-care syphilis tests using archived sera. Sex Transm Infect 2006; 82(Suppl 5): v7-12
[46] Tinajeros F, Grossman D, Richmond K, et al. Diagnostic accuracy of a point-of-care syphilis test when used among pregnant women in Bolivia. Sex Transm Infect 2006; 82(Suppl V): 17-21.

[47] Campos PE, Buffardi AL, Chiappe M, et al. Utility of the determine syphilis TP rapid test in commercial sex venues in Peru. Sex Transm Infect 2006; 82(Suppl V): 22-5.

[48] Bronzan RN, Mwesigwa-Kayongo DC, Narkunas D, et al. Onsite rapid antenatal syphilis screening with an immunochromatographic strip improves case detection and treatment in rural South African clinics. Sex Transm Dis 2007; 34: S55-S60.

[49] Mabey D, Peeling RW, Ballard R, et al. Prospective, multi-centre clinic-based evaluation of four rapid diagnostic tests for syphilis. Sex Transm Infect 2006; 82(Suppl v): v13-16,

[50] Creegan L, Bauer HM, Samuel MC, Klausner J, Liska S, Bolan G. An evaluation of the relative sensitivities of the venereal disease research laboratory test and the Treponema pallidum particle agglutination test among patients diagnosed with primary syphilis. Sex Transm Dis 2007; 34: 1016.

[51] Vickerman P, Peeling RW, Terris-Prestholt F, et al. Modeling the costeffectiveness of introducing rapid syphilis tests into a antenatal syphilis screening programme in Mwanza, Tanzania. Sex Transm Infect 2006; 82 (Suppl V): v38-43.

[52] Schackman BR, Neukermans CP, Fontain SNN, Nolte C, Joseph P. Cost-effectiveness of rapid syphilis screening in prenatal HIV testing programs in Haiti. PLoS Med 2007; 4: 183.

[53] Levin CE, Steele M, Atherly D, et al. Analysis of the operational costs of using rapid syphilis tests for the detection of maternal syphilis in Bolivia and Mozambique. SexTransm Dis 2007; 34: S47-S54.

[54] Blandford JM, Gift T, Vasaiker S, et al. Cost-effectiveness of on-site antenatal screening to prevent congenital syphilis in rural Eastern Cape Province, Republic of South Africa. Sex Transm Dis 2007; 34: S61.

[55] Peeling RW, Mabey D, Fitzgerald DW, Watson-Jones D. Avoiding HIV and dying of syphilis. Lancet 2004; 364: 1561-3.

[56] United States Centers for Disease Control and Prevention. Sexually transmitted diseases treatment guidelines 2006. Morb Mortal Wkly Rep Recomm 2006; 55(RR-11): 1-94.

[57] Public Health Agency of Canada. STI Management Guidelines. Available from: http//:www.phac-aspc.gc.ca/dpg-eng.php

[58] Kuypers J, Gaydos CA, Peeling RW. Principles of laboratory Diagnosis of STIs. In: Holmes KK, Sparling PF, Stamm WE, et al., Eds. Sexually transmitted diseases. $4^{\text {th }}$ ed. New York: MeGraw Hill 2008; pp. 937-57.

[59] Gaydos CA, Theodore M, Dalesio N, Wood BJ, Quinn TC. Comparison of three nucleic acid amplification tests for detection of Chlamydia trachomatis in urine specimens. J Clin Microbiol 2004; 42: 3041-5.

[60] Schachter J, Chernesky MA, Willis DE, et al. Vaginal swabs are the specimens of choice when screening for Chlamydia trachomatis and Neisseria gonorrhoeae: results from a multicenter evaluation of the APTIMA assays for both infections. Sex Transm Dis 2005; 32: 725-8.

[61] Chernesky MA, Hook EW III, Martin DH, et al. Women find it easy and prefer to collect their own vaginal swabs to diagnose Chlamydia trachomatis or Neisseria gonorrhoeae infections. Sex Transm Dis 2005; 32: 729-33.

[62] Hobbs MM, Van Der Pol B, Totten P, et al. From the NIH: Proceedings of a workshop on the importance of self-obtained vaginal specimens for detection of sexually transmitted infections. Sex Transm Dis 2008; 35 8-13.

[63] Hoebe CJPA, Rademaker CW, Brouwers EEHG, Ter Waarbeek HLG, Van Bergan JEAM. Acceptability of self-taken vaginal swabs and firstcatch urine samples for the diagnosis of urogenital Chlamydia trachomatis and Neisseria gonorrhoeae with an amplified DNA assay in young women attending a public health sexually transmitted disease clinic. Sex Transm Dis 2006; 33: 491-5.

[64] Jones HE, Altini L, de Kock A, Young T, van de Wijgert JHHM. Home-based $v s$ clinic-based self-sampling and testing for sexually transmitted infections in Gugulethu, South Africa: randomised trial. Sex Transm Infect 2007; 83: 552-7.

[65] Lippman SA, Jones HE, Luppi CG, Pinho AA, Veras MAMS, van de Wijgert JHHM. Home-based self-sampling and self-testing for sexually transmitted infections: Acceptable and feasible alternatives to providerbased screening in low-income women in Sao Paulo, Brazil. Sex Tansm Dis 2007; 34: 421-8.

[66] Novak DP, Lindholm L, Jonsson M, Karlsson RB. A Swedish costeffectiveness analysis of community-based Chlamydia trachomatis PCR testing of postal urine specimens obtained at home. Scand J Public Health 2004; 32: 324-32. 
[67] van Valkengoed IG, Postma MJ, Morre SA, et al. Cost effectiveness analysis of a population based screening programme for asymptomatic Chlamydia trachomatis infections in women by means of home obtained urine specimens. Sex Transm Infect 2001; 77: 276-82.

[68] Gaydos CA. Rapid tests for sexually transmitted diseases. Curr Infect Dis Rep 2006; 8: 115-24.

[69] Benzaken AS, Galban EG, Antunes W, et al. The diagnosis of gonococcal infection in high risk women using a rapid test. Sex Transm Infect 2006; 82 (Suppl v): v26-28

[70] Alary M, Gbenafa-Agossa C, Aina G, et al. Evaluation of a rapid pointof-care test for the detection of gonococcal infection among female sex workers in Benin. Sex Transm Infect 2006; 82(Suppl v): v29-32.

[71] Yin YP, Peeling RW, Chen XS, et al. Clinic-based evaluation of clearview Chlamydia MF for detection of Chlamydia trachomatis in vaginal and cervical specimens from women at high-risk in China. Sex Transm Infect 2006; 82 (suppl v): v33-37.

[72] Saison F, Mahilum-Tapay L, Michel CC, et al. Prevalence of Chlamydia trachomatis infection among low- and high-risk Filipino women and performance of Chlamydia rapid tests in resource-limited settings. J Clin Microbiol 2007; 45: 4011-7.

[73] Mahilum-Tapay L, Laitila V, Wawrzyniak JJ, et al. New point of care Chlamydia Rapid Test-bridging the gap between diagnosis and treatment: performance evaluation study. BMJ 2007; 335; 1190-4.

[74] Gift TL, Pate MS, Hook EW, Kassler WJ. The rapid test paradox: when fewer cases detected led to more cases treated. Sex Transm Dis 1999; 26: $232-40$.

[75] Vickerman P, Watts C, Alary M, Mabey D, Peeling RW. Sensitivity requirements for the point of care diagnosis of Chlamydia trachomatis and Neisseria gonorrhoeae. Sex Transm Infect 2003; 79:363-7.

[76] Vickerman P, Watts C, Peeling RW, Mabey D, Alary M. Modeling the impact and cost-effectiveness of rapid point-of-care diagnostic tests in an STI treatment intervention in Cotonou, Benin. Sex Transm Infect 2006; 82: 403-12.

[77] Kissinger P, Amedee A, Clark RA, et al. Trichomonas vaginalis treatment reduces vaginal HIV-1 shedding. Sex Transm Dis 2009; 36 : 11.

[78] Sewankambo N, Gray RH, Wawa MJ, et al. HIV-1 infection associated with abnormal vaginal flora morphology and bacterial vaginosis. Lancet 1997; 350: 546.

[79] Martin HL, Richardson BA, Nyange PM, et al. Vaginal lactobacilli, microbial flora, and risk of human immunodeficiency virus type 1 and sexually transmitted disease acquisition. J Infect Dis 1999; 180: 1863-8.

[80] Huppert JS, Batteiger BE, Braslins $\mathrm{P}$, et al. Use of an immunochromatographic assay for rapid detection of Trichomonas vaginalis in vaginal specimens. J Clin Microbiol 2005; 43: 684-7.

[81] Miller GA, Klausner JD, Meza R, et al. Assessment of a rapid antigen detection system for Trichomonas vaginalis infection. Clin Diag Lab Immunol 2003; 10: 1157.

[82] Hillier S, Marrazzo J, Holmes KK. Bacterial Vaginosis. In: Holmes KK, Sparling PF, Stamm WE et al., Eds. Sexually Transmitted Diseases. 4th ed. New York: MeGraw Hill 2008: pp. 737-68.

[83] Myziuk L, Romanowski B, Johnson SC. BV Blue test for diagnosis of bacterial vaginosis. J Clin Microbiol 2003; 41: 1925-8.

[84] Bradshow CS, Morton AN, Garland SM, Horvath LB, Kuzevska I, Fairley CK. Evaluation of a point-of-care test, BVBlue, and clinical and laboratory criteria for diagnosis of bacterial vaginosis. J Clin Microbiol 2005; 43: 1304-8.

[85] Wiggins R, Crowley T, Horner PJ, Soothill PW, Millar MR, Corfield AP. Use of 5-bromo-4-chloro-3-indoyl-a-D-N-acetylneuraminic acid in a novel spot test to identify sialidase activity in vaginal swabs from women with bacterial vaginosis. J Clin Microbiol 2000; 38: 3096-7.

[86] West B, Morrison L, Van Der Leoff MS, et al. Evaluation of a new rapid diagnostic kit (FemExam) for bacterial vaginosis in patients with vaginal discharge syndrome in The Gambia. Sex Transm Dis 2003; 30: 483-9.
[87] Gallo MF, Warner L, Macaluso M, et al. Risk factors for incident herpes simplex type 2 virus infection among women attending a sexually transmitted disease clinic. Sex Transm Dis 2008; 35: 679.

[88] Gardella C, Krantz E, Daruthayan C, Drolette L, Corey L, Wald A. The acceptance of HSV-testing partners of HSV-2 seronegative pregnant women. Sex Transm Dis 2009; 36: 211.

[89] Fitzgerald DW, Behets FMTF. Beyond Folklore. J Am Med Assoc 2002; 288: 2791-2

[90] Gloyd S, Montoya P, Floriano F, Chadreque MC, Pfeiffer J, GimbelSherr K. Scaling up antenatal syphilis screening in Mozambique: transforming policy to action. Sex Transm Dis 2007; 34: S31.

[91] Petti CA, Polage CR, Quinn TC, Ronald AR, Sande MA. Laboratory medicine in Africa: a barrier to effective health care. Clin Infect Dis 2006; 42: 377-82

[92] Oliff M, Mayaud P, Brugha R, Semakafu AM. Integrating reproductive health services in a reforming health sector: the case of Tanzania. Reprod Health Matters 2003; 11: 37-48.

[93] Pang T, Peeling RW. Diagnostic tests for infectious diseases in the developing world: two sides of the coin. Trans R Soc Trop Med Hyg 2007; 101: 856-7.

[94] World Health Organization. Regulation of in vitro diagnostics: a global perspective. Annex in: diagnostics for tuberculosis: global demand and market potential. Geneva: WHO 2006; pp. 194-203.

[95] Peeling RW, Smith PJ, Bossuyt PMM. A guide for diagnostic evaluations. Nat Microbiol Rev 2006; Suppl: S2-S6. Available from: http//: www.nature.com/nrmicro/supplements

[96] Plate DK on behalf of the Rapid HIV Test Evaluation Working Group. Evaluation and implementation of rapid HIV tests: the experience in 11 African countries. AIDS Res Hum Retroviruses 2007; 23: 1491-8.

[97] World Health Organization. Primary health care: now more than ever. The World Health Report 2008.

[98] Ministry of Health and Population, Malawi. Essential Medical Laboratory Services Project, Malawi 1998-2002. Final Report published in 2003.

[99] Schmid GP, Stoner BP, Hawkes S, Broutet N. The need and plan for global elimination of congenital syphilis. Sex Transm Dis 2007; 34: S5.

[100] Fraser CM, Norris SJ, Weinstock GM, et al. Complete genome sequence of Treponema pallidum, the syphilis spirochete. Science 1998; 281:375-81.

[101] Stephens RS, Kalman S, Lammel C, et al. Genome sequence of an obligate intracellular pathogen of humans: Chlamydia trachomatis. Science 1998; 282: 754-9.

[102] Pohlner J, Halter R, Beyreuther K, Meyer TF. Genome structure and extracellular secretion of Neisseria gonorrhoeae IgA protease. Nature 1987; 325: 458-62.

[103] Sorger PK. Microfluidics closes in on point of care assays. Nat Biotechnol 2008; 26: 1345-6.

[104] Lewin Group. The value of diagnostics: innovation, adoption and diffusion into health care 2005.

[105] WHO Task Force on Health Economics. Cost containment and cost analysis of TB control programmes: the case of Malawi 2003.

[106] Hay Burgess DC, Wasserman J, Dahl CA. Global health diagnostics. Nature 2006; S1: 1-2. (23 November 2006). doi:10.1038/nature05440.

[107] Urdea M, Penny LA, Olmsted SS, et al. Requirements for high impact diagnostics in the developing world: nature supplement: determining the global health impact of improved diagnostic technologies for the developing world. Nature 2006; S1: 73-9.

[108] Aledort JE, Ronald A, Rafael ME, et al. Reducing the burden of sexually transmitted infections in resource-limited settings: the role of improved diagnostics. Nature 2006; 444(Suppl 1): 59-72.

[109] Peeling RW, Mabey D, Herring A, Hook EW 3rd. Why do we need quality assured rapid diagnostic tests for sexually transmitted infections? Nat Rev Microbiol 2006; 4: 909-21.

[110] Mboya-Okeyo T, Ridley RG, Nwaka S. The African network for Drugs and diagnostics innovation. Lancet 2009; 373: 1507-8.

[111] Point-of-Care Technologies Research Network. Available from: http//: www.nibib.nih.gov/research/POCTRN 